\title{
Complicated posterior capsulorhexis: aetiology, management, and outcome
}

\author{
Françoise Van Cauwenberge, Jean-Marie Rakic, Albert Galand
}

\begin{abstract}
Background-A 1 year retrospective analysis of 650 patients, who underwent a posterior capsulorhexis on their intact capsules, was performed to examine the incidence of complications, their aetiologies, and the outcome.

Methods-Data were analysed on 32 patients with complicated capsulorhexis for type of surgery, preoperative and postoperative factors, and relative risk factors for vitreous issue.

Results-There were six patients with vitreous loss. The posterior capsulorhexis was uncontrolled in $\mathbf{1 4}$ cases and difficult to perform in 12 cases. Implantation into the capsular bag was possible in all cases. Systemic vascular hazard and old age (over 80 years) were found to be statistically significant risk factors for vitreous loss $(p=0.002$ and $p=0.03$ respectively). The mean follow up was 13.5 months (range 4-25 months). One patient developed a retinal detachment and two had a transient clinical cystoid macular oedema. Visual acuity of $\geq 20 / 40$ was obtained in $93 \%$ of the patients.

Conclusion-Loss of control of the posterior capsulorhexis has a low incidence but can lead to serious problems during surgery. A good knowledge of the technique is necessary to complete the procedure with a posterior capsulorhexis of the optimum size without vitreous loss.

(Br F Ophthalmol 1997;81:195-198)
\end{abstract}

'After-cataract' (also referred to as posterior capsule opacification or secondary cataract) is the most important challenge to modern extracapsular cataract extraction (ECCE), with an estimated incidence approaching $50 \%$ after 5 years. ${ }^{12}$ Most surgeons currently rely on the Nd:YAG laser to perform posterior capsulotomy at a later stage if the capsule opacifies. There are some disadvantages to YAG laser therapy including vision threatening complications, and increased overall cost of cataract treatment. ${ }^{3}$ In a continuous attempt to prevent or at least delay the occurrence of this complication, and since a posterior capsulorhexis has been advocated by others in case of posterior capsule rupture ${ }^{4}$ or in paediatric cataract extraction, ${ }^{5-7}$ we started to perform regularly a posterior continuous circular capsulorhexis (PCCC) on our adult patients with intact capsules before intraocular lens (IOL) implantation.

The theoretical advantage of this technique is to remove the support for lens epithelial cell migration and proliferation in the central visual axis. We started performing that manoeuvre in August 1993 and since then have performed a PCCC on more than 1300 patients. Determination of long term efficiency and frequency of side effects obviously need a long follow up period and a comparison with the current standard treatment by YAG laser therapy so the study regarding these aspects is still ongoing. The study reported here was aimed at investigating the intraoperative complications encountered during the first year of this practice, their aetiology, management, and visual outcome.

\section{Materials and methods}

From a 1 year retrospective analysis of medical charts, 32 cases of complicated PCCC on intact capsules were identified in a cohort of 650 patients with PCCC (5\%). Complicated PCCC was defined by the peroperative observation of vitreous passage into the anterior segment, tears in the posterior capsule, uncontrolled size or location of the PCCC, or technical difficulty in PCCC performance. These 32 cases represent all the unplanned problems encountered with the posterior capsule, and they were further analysed for type of surgery, preoperative and postoperative factors, and relative risk factors for vitreous issue. Background ocular pathology (Table 1), where it was felt that visual outcome could be suboptimal, was present in 16 patients $(50 \%)$. Table 2 gives age, sex, axial length, and preoperative intraocular pressure (IOP) characteristics. Only one case was carried out under local anaesthesia (via an inferotemporal peribulbar injection of $4 \mathrm{ml}$ lignocaine $2 \%$ ). The rest were operated under general anaesthesia. The surgeons performing the procedure were two of the authors (FV and AG). No device was used preoperatively to lower vitreous pressure.

After either corneal incision $(90.6 \%)$ or fornix based flap (9.4\%), an anterior circular

Table 1 Background ocular pathology

\begin{tabular}{ll}
\hline Diagnosis & No of cases \\
\hline Signs of macular degeneration & 9 \\
Optic atrophy & 1 \\
Cornea guttata & 3 \\
Corneal scars & 1 \\
Axial length $>26 \mathrm{~mm}$ & 6 \\
\hline
\end{tabular}

Accepted for publication 4 November 1996 
Table 2 Population data

\begin{tabular}{ll}
\hline Age (years) & 73.9 (range 19-88) \\
Sex & 10 males, 22 females \\
Axial length $(\mathrm{mm})$ & 23.9 (range 21.6-29.0) \\
Preoperative IOP $(\mathrm{mm} \mathrm{Hg})$ & 15.0 (range 10.0-22.0) \\
Systemic vascular risk & 4 patients \\
\hline
\end{tabular}

*Vascular risk was defined by the presence of at least two of the following factors: hypertension, history of infarct, presence of angina pectoris, or diabetes mellitus.

capsulorhexis was created. This was followed by phacoemulsification ( $41 \%$ ), nucleus reduction $(28 \%),{ }^{8}$ Kansas technique $(19 \%),{ }^{9}$ or, for patients with a very soft nucleus, irrigation aspiration only (12\%). Before the insertion of an intraocular lens, a hole was created with a 30 gauge needle in the posterior capsule, viscoelastic substance was injected through the hole and a PCCC was attempted. Complications appeared and were handled as discussed below. After removal of the viscoelastic, the self sealing incision was sutured, and a drop of $\beta$ blocker was immediately applied. Intravenous acetazolamide was systematically administered.

Statistical analysis of the relative risk factors involved in vitreous loss was performed with the odds ratio (OR) method and the $\chi^{2}$ test.

\section{Results}

A complete overview of the incidence of each type of complication is given in Table 3 . The most frequent problem was to perform a central capsulorhexis of the optimum size $(<5$ $\mathrm{mm}$ diameter). This was not possible in 14 cases, and in 12 cases a PCCC was carried out with great difficulty because of either insufficient visibility during the procedure or an anatomically changed capsule (floppy or fibrotic in its centre).

Table 4 gives the patient characteristics and the type of procedure in cases with vitreous

Table 3 Incidence of complications during posterior continuous circular capsulorhexis (PCCC)

\begin{tabular}{lc}
\hline Type of complication & Incidence (\%) \\
\hline Vitreous loss & $6(19)$ \\
Uncontrolled PCCC without vitreous: & $14(44)$ \\
tears in the posterior capsule & $3(21)$ \\
too large and eccentric PCCC & $7(50)$ \\
too large PCCC & $3(22)$ \\
eccentric PCCC & $1(7)$ \\
Controlled but difficult PCCC: & $12(37)$ \\
poor visibility during the procedure & $5(42)$ \\
floppy capsule & $3(25)$ \\
fibrotic capsule & $3(25)$ \\
difficult implantation & $1(8)$ \\
\hline
\end{tabular}

Table 4 Details of the cases with vitreous loss

\begin{tabular}{lllll}
\hline Age & Sex & $\begin{array}{l}\text { Systemic risk } \\
\text { factors }\end{array}$ & $\begin{array}{l}\text { Type of } \\
\text { surgery }\end{array}$ & Miscellaneous \\
\hline 73 & M & yes & Phaco & yes \\
82 & F & no & Manual & no \\
84 & F & no & Manual & yes $\dagger$ \\
82 & M & yes & Manual & no \\
85 & M & no & Manual & no \\
81 & F & yes & Manual & no \\
\hline
\end{tabular}

*Vitreous positive pressure secondary to enlarging the corneal incision with the $5.2 \mathrm{~mm}$ blade.

†Traction on the border of the non-circular posterior capsulorhexis during IOL implantation. loss. Risk factors were found to be the presence of multiple vascular problems $(\mathrm{OR}=25$, $\left.\chi^{2}=9.5, \mathrm{p}<0.002\right)$, age over 80 years $(\mathrm{OR}=9.4$, $\left.\chi^{2}=4.7, \mathrm{p}=0.03\right)$, and manual extraction of the nucleus $\left(\mathrm{OR}=4.2, \chi^{2}=1.8\right.$, not statistically significant). These six cases necessitated the use of anterior dry vitrectomy before the implantation of the IOL.

Tears in the posterior capsule were created during the opening of the capsule with vitreous positive pressure (one case), during injection of viscoelastic with exaggerated pressure in the PCCC (one case), and during the IOL implantation in a non-circular posterior capsulorhexis (one case).

In the 11 cases demonstrating too large and/or eccentric PCCC, the loss of control of the size and of the location of the PCCC occurred during viscoelastic injection in eight cases (viscoelastic was injected under too much pressure or with air bubbles), as a result of positive vitreous pressure in one case, poor visibility in another case, and without identifiable reason in one case.

Finally, in 12 patients, the procedure was controlled but technically difficult. The problem involved mainly the quality of the posterior capsule which was either floppy and located very deeply in the eye or fibrotic in its centre making the control difficult since the fibrotic plaque tends to direct the size and the location of the PCCC. A poor visibility during the procedure was the consequence of a damaged cornea (two cases), myotic pupil (one case), air bubbles in viscoelastic (one case), and improper position of the coaxial light as regards the position of the PCCC (one case).

In all these cases, after a thorough checkup of the capsular stability under the iris, endocapsular implantation was performed during the initial procedure.

Table 5 details the results of the examination performed on the first postoperative day. Table 6 gives the postoperative complications related to the performance of a PCCC with a mean follow up of 13.5 months (range 4 to 25). The mean IOP was $14.1 \mathrm{~mm} \mathrm{Hg}$ (range 8-24) and no case resulted in chronic glaucoma. The visual performance was good (mean visual acuity of $32 / 40$, range $20 / 60-60 / 60$ ). Only two patients with macular degeneration had visual

Table 5 Clinical presentation on the first postoperative day

\begin{tabular}{lr}
\hline Type of complication & No \\
\hline $\begin{array}{l}\text { Corneal oedema }(\mathrm{n}=17): \\
\quad \text { mild }\end{array}$ & 12 \\
$\quad$ moderate & 4 \\
$\quad$ severe & 1 \\
IOP (mean $=18.7 \mathrm{~mm} \mathrm{Hg})$ & 5 \\
$\quad>25 \mathrm{~mm} \mathrm{Hg}$ & \\
Visual acuity (mean $=24 / 40)$ & 6 \\
$\quad<6 / 60$ \\
Vitreous present in the anterior chamber & 4 \\
\hline
\end{tabular}

Table 6 Postoperative complications

\begin{tabular}{ll}
\hline Type of complication & No \\
\hline Vitreous in the anterior chamber & 4 \\
Cystoid macular oedema (clinical) & 2 \\
Eccentric IOL & 1 \\
Retinal detachment & 1 \\
\hline
\end{tabular}


acuity under $20 / 40$. Five out of six patients, in whom vitreous was present in the anterior chamber, already had vitreous loss during the procedure. The only patient who developed this complication postoperatively had a PCCC larger than the size of the optic.

\section{Discussion}

There are currently three main strategies in the research of after-cataract prevention. The first, by analogy with the experience acquired in glaucoma, involves the application of antiproliferative drugs in the capsular bag. ${ }^{10}$ The second is oriented towards complete removal of epithelial cells from the capsule during surgery (diathermy) $)^{11}$ or after a latent period (toxins coupled with a specific antibody or a growth factor)..$^{12} 13$ The third tries to preserve a clear central axis for a long period of time (IOL geometry and biochemistry, ${ }^{14}$ equatorial rings,${ }^{15}$ removal of the central posterior capsule during the initial procedure).

Posterior capsulorhexis has been introduced in cataract surgery for paediatric cataract extraction or for extracapsular surgery complicated by capsular disruption. There are, however, no reports in the literature on the possible intraoperative or postoperative complications of these cases. We have extended the indications of this procedure to the majority of our cases presenting an intact capsule at the end of cataract extraction. Our analysis of 32 cases of complicated PCCC (due either to vitreous passage into the anterior segment, loss of control of the rhexis, or problems in obtaining a continuous circular centred rhexis) highlighted the contributing factors to the problems observed.

The only statistically significant relative risk factors for vitreous loss during the procedure were found to be systemic cardiovascular disease and age over 80 years. This is in accordance with previous studies which suggested a relation between positive vitreous pressure and coexisting vascular problems. ${ }^{16}$ Our six cases with vitreous loss necessitated the use of anterior dry vitrectomy with viscoelastics to prevent further vitreous hydration. The anterior vitrectomy was probably not complete enough since half of these cases still had vitreous in the anterior chamber the next day. Another possibility is that, even if the vitrectomy were complete, a small amount of vitreous somehow found its way towards the anterior segment through the posterior rhexis. One case in our series developed vitreous in the anterior chamber while vitreous loss was not noticed immediately after the operation. The reason was probably a PCCC size larger than the size of the optic.

The control of the PCCC was lost mainly during injection of viscoelastic under too high pressure or with air bubbles in it. The posterior capsule is very thin and exquisitely sensitive to minor variations of pressure around its plane, especially after a small hole has been created in its centre. The viscoelastic should ideally be checked for the presence of air bubbles in the syringe before insertion into the eye and it should be injected very carefully to push the anterior hyaloid membrane backwards without creating a large difference of pressure between the anterior and posterior faces of the posterior capsule.

PCCC should be performed with great care in eyes having coexistent abnormalities that preclude a clear view of the posterior capsule or in eyes in which the posterior capsule is located very deeply (at the limit of focus of the operative microscope). Patients with a myotic pupil or a damaged cornea are obviously not good candidates.

Another potential problem was occasionally the presence of a fibrous plaque on the posterior capsule which, by itself is a good indication, but which can also direct, by its position, the size and the form of the rhexis.

Different authors have expressed concern about the increased difficulty of implantation once the posterior capsule has been opened. ${ }^{17}$ PCCC performance after IOL implantation has the advantage of reducing problems with implantation on an opened capsule. This timing, in our opinion, increases overall the technical difficulty of PCCC realisation. Insertion of the IOL in the capsular bag was always possible in our patients despite the complications encountered. We performed, however, in every doubtful case, a thorough check up of the capsular bag stability with the aid of an iris retractor.

Nearly half of our patients showed a mild to moderate corneal oedema on the first postoperative day. This was probably the result of increased operation time and increased instrumentation. Only five cases had elevated IOP (over $25 \mathrm{~mm} \mathrm{Hg}$ ) which necessitated the administration of intravenous osmotic agents, despite the extensive use of viscoelastics for the PCCC realisation and for the management of the complications. The low number of elevated IOP is probably related to the systematic use of prophylactic $\beta$ blockers and intravenous acetazolamide at the end of surgery in all our cases with a complicated PCCC, since the viscoelastic in the posterior segment was only partly removed.

Table 6 lists the postoperative complications found in our series after a mean follow up of 13.5 months. One patient developed a retinal detachment 8 months after the procedure and was successfully treated with scleral buckling. It was felt unjustifiable to perform fluorescein angiography for study purposes only on all our patients. Fluorescein angiography was performed on the first 50 consecutive patients with uncomplicated PCCC; the incidence of angiographic cystoid macular oedema was found to be $6 \% .{ }^{18}$ We observed, in the complicated PCCC series, two cases of clinically significant cystoid macular oedema, which spontaneously regresses over a period of 6 months. Other authors did not mention occurrence of cystoid macular oedema in their series. ${ }^{19}$ Chambless found an incidence of $7 \%$ in phacoemulsification cases complicated by posterior capsule disruption. ${ }^{20}$

The visual prognosis after complicated PCCC can be very good; $93 \%$ of patients had corrected visual acuity $\geq 20 / 40$. This compares 
favourably with $77 \%$ in Gimbel's series, ${ }^{4}$ while half of our cases had background ocular pathology. However, a complicated PCCC in which all lens matter has already been removed is obviously an easier situation than a disruption of the posterior capsule at the beginning of the phacoemulsification.

Loss of control of the PCCC can lead to potential problems during surgery. Our analysis of 32 difficult cases suggests that old patients with serious systemic vascular disease, eyes with floppy or fibrotic capsules, and those offering us poor visibility during the procedure are not good candidates for the performance of a safe PCCC. A good knowledge of the technique, especially during the manipulation of viscoelastics around the posterior capsule is mandatory to complete the procedure with a posterior continuous circular centred capsulorhexis of the optimum size, without vitreous loss. The authors thank Professor Adelin Albert of the University of
Liege, for his help with statistical analysis, Professor Gijs Liege, for his help with statistical analysis, Professor Gijs
Vrensen from the Netherlands Ophthalmic Research Institute, Amsterdam, for his helpful discussion, and Mr Tony Lejeune for his assistance in manuscript preparation.

1 Sterling S, Wood T. Effect of intraocular lenses convexity on posterior capsule opacification. ₹ Cataract Refract Surg posterior capsu

2 Shah G, Gills J, Durham D, Ausmus W. Three thousand YAG lasers in posterior capsulotomies: an analysis of complications and comparison to polishing and surgical discission. Ophthalmic Surg 1986;17:473-7.

3 Steinert RF, Puliafito CA, Kumar SR, Dudak SD, Patel S. Cystoid macular edema, retinal detachment and glaucoma after Nd:Yag laser posterior capsulotomy. Am $\mathcal{F}$ Ophthalmol 1991;112:373-80.

4 Gimbel HV. Posterior capsule tears using phacoemulsification-causes, prevention and management. Eur f Implant Refract Surg 1990;2:63-9.
5 BenEzra D, Paez JH. Congenital cataract and intraocular lenses. Am f Ophthalmol 1983;96:311-4.

6 Blumenthal M. The round capsulorhexis capsulotomy and the rationale for $11.0 \mathrm{~mm}$ diameter IOL. Eur $\mathcal{F}$ Implant Refract Surg 1990;2:15-9.

7 Gimbel HV, DeBroff BM. Posterior capsulorhexis with optic capture: maintaining a clear visual axis after pediatric cataract surgery. 7 Cataract Refract Surg 1994;20:658-64.

8 Galand A, Garza O. Reduction du noyau. Technique manuelle d'ECCE avec incision moyenne. An Inst Barmanuelle d'ECCE a

9 Kansas PG, Sax R. Small incision cataract extraction and implantation surgery using a manual phacofragmentation technique. F Cataract Refract Surg 1988;14:328-30.

10 Legler UFC, Apple DJ, Assia EI, Bluestein EC, Castaneda VE, Mowbray SL. Inhibition of posterior capsule opacification: the effect of colchicine in a sustained drug delivery system. F Cataract Refract Surg 1993;19:462-70.

11 Emery J, Clark SD, Munsell M, Kelleher PJ. Inhibition of posterior capsule opacification with an immunotoxin specific for lens epithelial cells: eighteen month results of a phase I/II clinical study. Invest Ophthalmol Vis Sci 1996;37: (suppl) 758 .

12 Behar-Cohen FF, David T, D'Hermies F, Pouliquen YM, Buechler Y, Nova MP, et al. In vivo inhibition of lens regrowth by fibroblast growth factor 2-saporin. Invest Ophthalmol Vis Sci 1995;36:2434-48.

13 Apple DJ, Solomon KD, Tetz MR, Assia EI, Holland EY, Legler UFC, et al. Posterior capsule opacification. Surv Ophthalmol 1992;37:73-116.

14 Hara T, Hara T, Yamada Y. Equatorial ring for maintenance of the completely circular contour of the capsular bag equator after cataract removal. Ophthalmic Surg 1991;22. 358-9.

15 Bretton RH, Kash RL, Cooley R, Schanzlin DJ. The use of bipolar diathermy for the prevention of secondary cataracts. Invest Ophthalmol Vis Sci 1996;36:(suppl)768.

16 Speaker MG, Guerriero PN, Metja JA, Coad CT, Berger A, Marmor M. A case-control study of risk factors for intraoperative suprachoroïdal expulsive haemorrhage. $O p h$ thalmology 1991;98:202-10.

17 Rosenbaum AL, Masket S. Intraocular lens implantation in children. Am f Ophthalmol 1996;121:225-6.

18 Galand A, Van Cauwenberge F. Posterior capsulorhexis on intact and clear capsules in adults. 7 Cataract Refact Surg 1996;22:458-61.

19 Mulhern M, Kelly G, Barry P. Effects of posterior capsular disruption on the outcome of phacoemulsification surgery. Br f Ophthalmol 1995;79:1133-7.

20 Chambless WS. Phacoemulsification and the retina. Cystoid macular oedema. Ophthalmology 1979;86:2019-22. 